METHODS OF STUDYING THE CONCENTRATION AND

COMPOSITION OF THE SOIL SOLUTION

\author{
BY \\ F. W. PARKER \\ "I \\ UNIVERSITY OF WISCONSIN \\ PH. D. THESIS 1921
}

Agricultural Experiment Station, University of Wisconsin

REPRINTED FROM

. Soll Science, Vol. XII, No. 3, September, 1921 
\begin{tabular}{|} 
LIGRARY OF CONGRESS \\
REOSIVED \\
APR 61922 \\
DOCUMENTS DIVISIOR:
\end{tabular}

$\therefore$ 
Reprinted from SorL Screnca

Vol. XII, No. 3, September, 1921

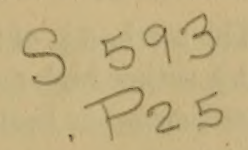

\title{
METHODS OF STUDYING THE CONCENTRATION AND COMPOSITION OF THE SOIL SOLUTION ${ }^{1}$
}

\author{
F. W. PARKER \\ Agricultural Experiment Station, Universily of Wisconsin \\ Received for publication March 7, 1921
}

A more exact knowledge of the soil solution is desirable for the study of many of the problems of soil fertility and related subjects. The purpose of the present investigation was to study some of the methods which have been used in determining the concentration and composition of the soil solution and to compare the results obtained by the different methods.

The methods which have been used may be classified into groups as follows:

(a) Methods involving extraction with comparatively large amounts of water.

(b) Methods which aim to obtain the true soil solution.

(c) Methods which aim to measure the concentration of the soil solution directly in the soil.

The water-extraction method has been widely used and possesses many advantages. The greatest criticism of the method is that the addition of a large quantity of water alters the equilibrium in the soil. It undoubtedly has a solvent effect and may also cause a precipitation of some of the material in solution due to an alteration in the nature of the solvent. The quantity of salts obtained depends upon a number of factors. Mitscherlich (17) has shown the effect of the $\mathrm{CO}_{2}$ content of the water, the time of extraction, and the ratio of soil to water on the quantity of material extracted. The procedure is arbitrary, but results obtained by several investigators indicate that the usual 1:5 extraction gives an approximate measure of the salt content of the soil solution.

Because of the lack of knowledge as to whether or not the water extraction gives a good quantitative measurement of the salts in the soil, there have been several methods proposed for obtaining the true soil solution.

Ramann, Marz and Bauer (21) have obtained the soil solution by the use of a hydraulic press. They applied a pressure of about 4,000 pounds to the square inch. Lipman (16) also used the pressure method, applying a maxi-

1 Part 1 of a thesis submitted at the University of Wisconsin in partial fulfillment of the requirements for the degree of Doctor of Philosophy. Published with the permission of the Director of the Wisconsin Agricultural Experiment Station.

The writer wishes to express his appreciation for the helpful suggestions and criticisms tendered by Prof. E. Truog. 
mum pressure of 53,000 pounds to the square inch. The method is of limited value for it is only applicable to finer-textured soils at a rather high moisture content and requires a complicated apparatus. The criticism has been made by Northrup (19) that the application of high pressures such as were used by Lipman would alter the physico-chemical equilibrium in the soil and as a result the true soil solution would not be secured.

The centrifuge method of Briggs and McLane (23) and the artificial root method of Briggs and McCall (8), in which suction is used, may give the true soil solution. However, these methods are only applicable to soils at high moisture contents and only small amounts of the solution are obtained.

The displacement method was first used by Schloesing (22). He used water colored with carmine to displace the soil solution and obtained considerable amounts which were used for analytical purposes. Gola (9) used water as the displacing liquid in his studies on the concentration of the soil solution. Ischerekov (15) used ethyl alcohol as the displacing liquid and obtained results which indicate that the displaced solution is the true soil solution in an unaltered condition. Moist soil was packed in a glass tube which had a piece of linen tied over the bottom. After placing alcohol on top of the soil column the soil solution soon began to drop from the bottom of the tube. He reports results which indicate that the successive portions of the displaced solution are of the same composition, and that the concentration of the soil solution is inversely proportional to the moisture content of the soil.

Van Suchtelen (25) modified Ischerekov's method by using paraffin oil as the displacing liquid and applying suction to hasten displacement. Morgan (18) used a combination of the pressure and displacement methods in which a heavy oil was used as the displacing liquid and applied pressures of about 500 pounds to the square inch to force the oil into the packed soil. Large quantities of the soil solution were thus obtained. The method is open to the objection that it requires a complicated apparatus and the use of a heavy oil makes it uncleanly.

The writer has been unable to find any reference in the literature in which a comparison was made of the results obtained by the displacement and water-extraction methods.

Several methods have been suggested for determining the concentration of the soil solution directly in the soil. Among the first of these was the measurement of the salt content by electrical conductance (10). The method is of some use in determinations of alkali in soils but the results are affected by the texture, organic matter, carbonates, and the moisture content of the soil. It has not proved of any great value in investigational work.

Bouyoucos and Mc.Cool $(5,6)$ have advanced the freezing-point method as a means of determining the concentration of the soil solution directly in the soil, and as a means of measuring the absolute salt content of the soil (7). The results obtained by this method will be discussed in the latter portion of this paper. 
In the present investigation a study was made of the displacement and freezing-point methods. The results obtained by displacement are compared with those obtained by the freezing-point and water-extraction methods.

\section{THE DISPLACEMENT METHOD}

\section{Description of the method and procedure}

The method consists of packing the moist soil in a cylinder provided with an outlet at the bottom. The displacing liquid is then poured on top of the soil column and as it penetrates the soil it displaces some of the soil solution which forms a zone of saturation below the displacing liquid. This zone increases in depth as it is continually forced downward by the pressure of the liquid above. When the saturated zone reaches the bottom of the soil column the clear soil solution, free of alcohol, drops from the soil as gravitational water.

The only apparatus required is a cylinder in which to pack the soil. The diameter of the soil column very largely determines the rate at which the soil solution will be obtained. The height of the soil column likewise determines the time required for displacement. These two factors must be considered in the selection of the cylinder to be used.

Three different-sized cylinders were used in the present investigation. Brass soil tubes 2 inches in diameter and 9 or 12 inches in depth were used in the preliminary work and when only small amounts of the soil solution were desired. Large brass soil tubes 3 inches in diameter were used for securing larger quantities of the solution and in studying the composition of successive portions of the displaced solution. These tubes were made in 6-inch sections and three or four sections were generally used. The bottom section was provided with a false screen bottom and a small outlet. Glass percolators, $2 \frac{3}{4}$ inches in diameter at the top and 15 inches deep, were used in most of the work. The bottom of the percolator was fitted with a small one-hole stopper. A small quantity of coarse quartz sand was placed in the percolator before adding the soil.

The soil was packed in the tubes by means of a short wooden rod. No difficulty was experienced in obtaining uniform packing. The degree of packing is determined by the kind of soil and its moisture content. Sandy soils were packed as firmly as possible at all moisture contents. Peats also may be packed firmly, for there is no danger of puddling the soil and rendering it impervious to the displacing liquid. With the heavier classes of soil care must be taken to prevent puddling during the packing, in which case the rate of displacement is exceedingly slow or entirely prevented. For this reason it is best to use the heavier soils at a moisture content somewhat below the optimum for plant growth. Under proper moisture conditions the soil should not stick together too readily when squeezed in the hand but should be rather granular and easily worked. Miami silt loam was best used at a moisture 
content of about 20 per cent and when properly packed had an apparent specific gravity of 1.50 to 1.60 . After a little experience one can readily determine the proper degree of packing for any soil at a given moisture content.

After packing, the cylinders were placed in ring stands and the displacing liquid added and maintained at a depth of 2 to 3 inches.

The time required for displacement varied widely, depending on the moisture content of the soil, the degree of packing, the soil type and the height of the soil column. In most cases it is possible to complete the displacement in 12 hours if the height of the soil column is not over 12 or 14 inches. The displacement may be stopped at any time by removing the layer of the displacing liquid on top of the soil column. In some cases the displacement was started in the evening and completed the next day. When silt loam soils were very firmly packed it sometimes required several days to complete the displacement.

In the water-extraction method the extracts were made by adding the desired amount of distilled water to the soil in a large mortar and stirring for 3 minutes. After settling 12 minutes the suspension was filtered through Pasteur-Chamberland filters.

In the displacement method filtration is unnecessary and total salts were determined by evaporating $25 \mathrm{cc}$. of the soil solution in a platinum crucible. In the water-extraction method larger quantities were evaporated in platinum dishes. After evaporation the crucibles and dishes were placed in an electric oven at $105^{\circ} \mathrm{C}$. for 12 hours. The weight of the residue represented total salts before ignition. The crucible and contenits were then ignited to constant weight to determine the total salts after ignition.

Nitrates were determined colorimetrically by the phenoldisulfonic acid method.

Calcium was determined volumetrically by titration of the oxalate with potassium permanganate.

Freezing-point determinations were made in the usual manner with a Beckman thermometer.

\section{The effect of different displacing liquids on the time and percentage displacement}

Water, ethyl alcohol, and paraffin oil were the liquids employed by previous investigators who used the displacement method. It seemed desirable to try other liquids to determine which would give the most complete and rapid displacement. In the preliminary work it was found that liquids which were non-miscible with water such as benzene, kerosene, ligroin, and ethyl acetate would not satisfactorily displace the soil solution. These liquids passed through the soil in practically an unaltered condition and displaced practically none of the soil solution. To use these liquids it would be necessary to pack the soil more and use pressure, as was done by Morgan (18).

The four liquids studied were ethyl alcohol, methyl alcohol, acetone and water. Miami silt loam at a moisture content of 21 per cent was packed in 
four 3-inch brass cylinders, care being taken to obtain uniform packing. The degree of packing in these cylinders was not great enough to obtain the most complete displacement. The time which elapsed between the addition of the displacing liquid and the appearance of the first drop of the soil solution was recorded. The volume of the water in the soil being known, the percentage displaced was readily calculated from the volume of the solution obtained. In order to detect the first appearance of the displacing liquid in the soil solution a freezing-point determination was used. The freezing point of successive portions of the solution was determined. As soon as the displacing liquid appeared in the solution the freezing point was appreciably changed. The appearance of ethyl alcohol and acetone was further confirmed by qualitative tests.

Table 1 shows the effect of different liquids on the time and percentage displacement. The viscosity of the liquids also is given in the table, since viscosity is one of the main factors influencing the time and percentage displacement. The less viscous displacing liquids pass through the pore spaces of

TABLE 1

The time and percentage displacement of the soil solution from Miami silt loam by different liquids

\begin{tabular}{|c|c|c|c|}
\hline DISPLACING LIQUID & $\begin{array}{l}\text { vIsccsiTy IN C. G. s. } \\
\text { UNITS AT } 20^{\circ} \mathrm{C} \text {. }\end{array}$ & $\begin{array}{l}\text { TIME TO THE FIRST } \\
\text { DROP }\end{array}$ & DISPLACEMENT \\
\hline & & hrs. & per cent \\
\hline 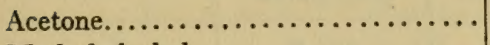 & 0.00334 & 2 & 12.0 \\
\hline 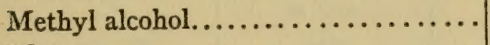 & 0.00591 & $3 \frac{1}{2}$ & 24.0 \\
\hline 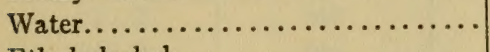 & 0.01006 & 4 & 20.0 \\
\hline Ethyl alcohol.................. & 0.01190 & $4 \frac{1}{2}$ & 36.0 \\
\hline
\end{tabular}

the soil more readily than do the more viscous liquids. This causes them to mix with a greater portion of the soil solution.

These and similar results obtained with other soils indicate that ethyl alcohol is the most satisfactory displacing liquid. It gives a more complete displacement than the other liquids used and it is very easy to test for its appearance in the displaced solution by means of the iodoform reaction.

Water is a fairly satisfactory displacing liquid but it mixes more with the soil solution and does not give as complete a displacement as does ethyl alcohol. If water is used some $\mathrm{NaCl}$ should be added making it possible to determine when the displacing solution appears by testing with silver nitrate.

Acetone is not at all satisfactory for it has too low a viscosity and therefore passes through the soil too readily, giving a very low percentage displacement. Methyl alcohol possesses no marked advantage over water and is not as good as ethyl alcohol.

Before ethyl alcohol was selected for subsequent work, additional experiments were made to determine the percentage displacement that would ordinarily be obtained by its use. The percentage displacement depends upon 
several factors. The higher the soil column and the more compact the soil, the greater will be the percentage of the soil solution displaced. A high moisture content also tends to produce a high percentage displacement. However, these same factors determine very largely the time required for displacement, and the time element should not be made too great.

The experiments indicated that it was practicable with most soils to obtain from 35 to 45 per cent of the soil solution by displacement with ethyl alcohol. This amount may be secured without the time element becoming very objectionable. It is possible to displace a much greater percentage than this. Using a silt loam soil at a moisture content of 23.3 per cent, a 75.6 per cent displacement was secured. Ischerekov (15) reports that with a soil at saturation it is possible to displace 95 per cent of the soil solution.

The concentration of the soil solution obtained by the use of different displacing liquids

A consideration of the mechanics of displacement leads to the conclusion that the soil solution obtained is in all cases really displaced by the soil solu-

TABLE 2

The concentration of the soil solution obtained with different displacing liquids

\begin{tabular}{|c|c|c|c|}
\hline \multirow{2}{*}{ DISPLACING LIQUTD } & \multicolumn{2}{|c|}{ TOTAL SALTS IN SOLUTION } & \multirow{2}{*}{$\begin{array}{l}\text { FREEZING-POINT } \\
\text { DEPRESSION } \\
\text { OF SOLUTION }\end{array}$} \\
\hline & Before ignition & After ignition & \\
\hline & $p \cdot p \cdot m$. & p.p. m. & ${ }^{\circ} \mathrm{C}$. \\
\hline Acetone..................... & 655 & 248 & 0.020 \\
\hline Methyl alcohol................... & 649 & 246 & 0.019 \\
\hline 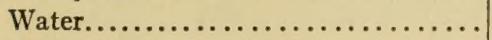 & 670 & 232 & 0.020 \\
\hline Ethyl alcohol.................. & 660 & 248 & 0.019 \\
\hline
\end{tabular}

tion itself. A zone, in which the soil is saturated with the soil solution, soon forms immediately below the displacing liquid after it is added. After the formation of this zone the only function of the displacing liquid is to give pressure and cause a downward movement of the saturated zone. Therefore, the displacing liquid should not affect the concentration of the solution obtained. The question of the influence of the displacing liquid on the concentration of the solution was studied experimentally, using the solutions secured from Miami silt loam by the different liquids shown in table 1 . The results are recorded in table 2 and confirm the conclusions reached by a theoretical consideration of the question.

\section{Composition of successive portions of the displaced solution}

In displacement the soil solution moves through the soil. The first portions move only a short distance before they drop from the soil, while the last portion may pass through a soil column of considerable height. The question 
at once arises as to whether or not the movement of the soil solution through the soil alters its composition. If it does, successive portions of the displaced solution would not be of the same composition. If they are not of the same composition the method probably would be of little value.

In a well mixed soil the solution in all portions is probably of the same composition. The readily soluble salts are in solution and this solution is in equilibrium with the surrounding solid material. As the solution is displaced and passes downward it comes in contact with more solution of the same composition and concentration and with solid material of the same nature as that from which it was displaced. Therefore, the point of equilibrium should not change and the composition of the solution should not be altered by its pas-

TABLE 3

The freezing-point depression and total salts in successive portions of the soil solution from Miami silt loam

\begin{tabular}{|c|c|c|c|}
\hline \multirow{2}{*}{ PORTION } & \multirow{2}{*}{$\begin{array}{l}\text { FREEZING-POINT } \\
\text { DEPRESSION }\end{array}$} & \multicolumn{2}{|c|}{ TOTAL SALTS IN SOLUTION } \\
\hline & & Before ignition & After ignition \\
\hline & ${ }^{\circ} \mathrm{C}$. & $p . p . m$. & p.p.m. \\
\hline 1 & 0.024 & & \\
\hline 2 & 0.023 & & \\
\hline 3 & 0.024 & & \\
\hline 4 & 0.025 & 352 & 168 \\
\hline 5 & 0.024 & & \\
\hline 6 & 0.022 & 360 & 176 \\
\hline 7 & 0.022 & 324 & \\
\hline 8 & 0.025 & 324 & 172 \\
\hline 9 & $0.076 \dagger$ & 344 & 180 \\
\hline 10 & $0.098 \dagger$ & 344 & 100 \\
\hline 11 & $0: 163 \dagger$ & 344 & 176 \\
\hline 12 & $0.309 \dagger$ & & 170 \\
\hline 13 & $0.444 \dagger^{\dagger}$ & $496^{*}$ & $256^{*}$ \\
\hline 14 & $0.689 \dagger$ & & \\
\hline
\end{tabular}

* High results due to colloidal material.

$\dagger$ High results due to alcohol in the solution.

sage through a column of soil which has been well mixed before it is packed in the cylinder. Hoagland, Martin and Stewart (14) have shown that a water extract of a soil when concentrated and allowed to percolate through another portion of the same soil does not alter much in its composition. It is therefore probable that the composition of the true soil solution would not be changed in passing through a soil column.

If the soil solution has a solvent effect on the soil particles during its passage through the soil, the last portions would be more concentrated than the first. To determine whether or not successive portions are of the same composition, as indicated by a determination of the freezing point and total salts, a 3-inch brass cylinder was filled with Miami silt loam containing 22 per cent moisture. 
The height of the soil column was 22 inches and 35.3 per cent of the soil solution was obtained. During displacement, successive portions were secured and the freezing point determined. Then portions 1 and 2, 3 and 4, 5 and 6 , etc., were combined and the total salts determined in these larger portions. Table 3 presents the results.

The first portion contained a small amount of colloidal material which caused a high result for total salts in that portion. Small amounts of alcohol began to come through in the ninth portion, as is indicated by the freezingpoint depression. However, the amount was so small that the total salts were not affected until the thirteenth portion. Then the solution became turbid due to colloidal material.

The results show that successive portions are of the same composition. Results have also been obtained showing that successive portions contain the same amount of nitrate nitrogen. It is probable that a complete analysis of the successive portions would prove that they were of the same composition in all respects. These results agree with those obtained by Ischerekov (15) and Schloesing (22). Ischerekov determined total salts and Schloesing determined nitrates.

\section{The concentration of the soil solution at different moisture contents}

In most soils the soil solution is very dilute. All readily soluble material is in solution even at low moisture contents. The solution is only saturated in respect to those minerals which are comparatively insoluble and have a low rate of solubility. Therefore, the addition of a small amount of water should not bring a very appreciable amount of material in solution. That soils are very insoluble and have a low rate of solubility has been shown by the work of Bouyoucos (2), in using the freezing-point method. That being the case, the concentration of the soil solution should be approximately inversely proportional to the moisture content of the soil. The displacement method is well adapted to such a study, for it can be used at a wide range of moisture contents. If the concentration of the soil solution obtained from a soil at different moisture contents is inversely proportional to the moisture content, it affords further proof that the method gives the true soil solution.

The relation of the moisture content and the concentration of the soil solution was studied in three soils. The soils had been in the greenhouse in a moist condition several weeks. Portions of the moist soil were weighed out; to some portions water was added to give the desired moisture content while others were allowed to dry to lower the moisture contents. Before packing in the percolators all portions except those at the higher moisture contents were passed through a coarse screen to insure thorough mixing. Displacement was started as soon after the addition of water as possible, usually within 4 to 6 hours.

Tables 4, 5 and 6 give the results obtained with Plainfield sand, Miami silt loam and Carrington silt loam. If the concentration is inversely propor- 
tional to the moisture content, the freezing-point depression of the solution multiplied by the moisture content of the soil will give a constant ( $D: M=$ $K)$. Also the parts per million of total salts in the dry soil will be a constant.

TABLE 4

The freezing-point depression of the soil solution and the total salts in Plainfield sand at rarying moisiure contents

\begin{tabular}{|c|c|c|c|c|}
\hline \multirow{2}{*}{ MOISTURE CONTENT } & \multirow{2}{*}{$\begin{array}{l}\text { PREEZING-POINT } \\
\text { DEPRESSION } \\
\text { OF SOLUTION }\end{array}$} & \multirow{2}{*}{$K(D \cdot M=K)$} & \multicolumn{2}{|c|}{ TOTAL SALTS IN SOI } \\
\hline & & & Before ignition & After ignition \\
\hline per cent. & ${ }^{\circ} \mathrm{C}$. & & p.p. $m$. & p.p.m. \\
\hline 4.25 & 0.045 & 0.191 & 62 & 13.1 \\
\hline 6.31 & 0.030 & 0.189 & 45 & 13.7 \\
\hline 8.30 & 0.022 & 0.182 & 57 & 12.9 \\
\hline 10.70 & 0.018 & 0.192 & 50 & 14.7 \\
\hline 12.40 & 0.014 & 0.173 & 49 & 14.1 \\
\hline 15.00 & 0.013 & 0.195 & 54 & 15.1 \\
\hline
\end{tabular}

TABLE 5

The freesing-point depression of the soil solution and the total salts in Miami silt loan at varying moisture contents

\begin{tabular}{|c|c|c|c|c|}
\hline \multirow{2}{*}{ MOISTURE CONTENT } & \multirow{2}{*}{$\begin{array}{l}\text { FREEZING-PONNT } \\
\text { DEPRESSION } \\
\text { OF SOLUIION }\end{array}$} & \multirow{2}{*}{$K(D \cdot M=K)$} & \multicolumn{2}{|c|}{ TOTAL SALTS IN SOIE } \\
\hline & & & Before ignition & After ignition \\
\hline per cent & ${ }^{\circ} \mathrm{C}$. & & D.p.m. & p.p. m. \\
\hline 10.30 & 0.039 & 0.401 & 116.8 & 44.4 \\
\hline 13.55 & 0.030 & 0.406 & 116.1 & 47.1 \\
\hline 17.25 & 0.022 & $0.379-$ & 104.3 & 43.4 \\
\hline 20.62 & $0.018^{\circ}$ & 0.371 & 108.9 & 44.8 \\
\hline 29.41 & 0.013 & 0.382 & & \\
\hline 34.05 & 0.012 & 0.408 & & \\
\hline
\end{tabular}

TABLE 6

The freeaing-point depression of the soil solution and the total salts in Carrington silt loant at varying moisture contents

\begin{tabular}{c|c|c|c|c}
\hline MOISTURE CONTENT & $\begin{array}{c}\text { FREEZING-POINT } \\
\text { DEPRESSION } \\
\text { OE SOLUTION }\end{array}$ & $K(M \cdot D=K)$ & \multicolumn{2}{|c}{ TOTAL SALIS IN SOIL } \\
\hline percent & ${ }^{\circ} \mathrm{C}$ & & Before ignition & After ignition \\
\hline 8.77 & 0.100 & 0.877 & 275 & p.p.m. \\
11.80 & 0.071 & 0.837 & 253 & 94.0 \\
13.95 & 0.067 & 0.934 & 253 & 92.3 \\
16.00 & 0.045 & 0.720 & 252 & 94.2 \\
18.55 & 0.043 & 0.797 & 253 & 95.3 \\
\hline
\end{tabular}

The results show that within experimental error $K$ and the parts per million of total salts are constants. Assuming that the concentration of the soil solution is inversely proportional to the moisture content, as is undoubt- 
edly very nearly the case, these results indicate that the true soil solution is obtained. Ischerekov (15) preformed a similar experiment and obtained results of the same order.

\section{A comparision of results obtained by displacement and water extraction}

In a study of any method it is desirable to compare results obtained by its use with those obtained by other methods. The water extraction method is the one most generally used in studying the soluble salt content of soils. It was therefore used as a means of further studying the results obtained by the displacement method. The two methods can not be expected to give the same results in all cases but the result should be of the same general order.

All nitrates are readily soluble and undoubtedly a very nearly correct quantitative determination of the nitrate nitrogen in the soil solution is

TABLE 7

Nitrate nitrogen in the dry soil as determined by the water-extraction and displacement methods

\begin{tabular}{c|r|c}
\hline \multirow{2}{*}{ SOIL NUMBER } & \multicolumn{2}{|c}{ NITRATE NITROGEN IN THE DRY SCIL } \\
\cline { 2 - 3 } 1 & Displacement method & Water extraction \\
\hline 2 & p.p.m. & p.p. m. \\
3 & 4.5 & 4.0 \\
4 & 54.6 & 52.0 \\
5 & 31.0 & 34.0 \\
6 & 103.3 & 100.0 \\
7 & 53.2 & 50.0 \\
8 & 63.3 & 60.0 \\
9 & 17.3 & 20.0 \\
10 & 38.0 & 36.0 \\
& 2.4 & 2.8 \\
& 6.9 & 6.4 \\
\hline
\end{tabular}

secured by the usual 1.5 water extraction. Since all of the nitrates are probably in the soil solution before the addition of water, it should be possible to obtain the same results for nitrates in the soil by using the two methods. The results obtained with the two methods on a number of soils from different field plots and the greenhouse are given in table 7 .

The two methods, within experimental error, give the same result for nitrate nitrogen in the soils. We may therefore conclude that the displaced solution is of the same nitrate concentration as the solution in the soil. It is also evident that the solution is of the same concentration as the soil solution remaining in the soil. If this were not the case the results for nitrates would not agree. Probably the only difference between the displaced solution and the same solution as it existed in the soil, is that when in the soil it was under the influence of a physical force, adhesion, which held it to the soil particles.

A further comparison of the two methods was made by using Miamiand Carrington silt loam and determining the total salts and calcium. The water- 
extraction method cannot be expected to give exactly the same results for total salts and calcium as the displacement method, since the addition of a very large amount of water undoubtedly affects to some extent the amount of material in solution. As several investigators $(17,24)$ have shown, the results obtained by water extraction depend largely upon the ratio of soil to water. Therefore, it seemed desirable to use varying ratios of soil to water in the present case. The results are given in tables 8 and 9.

In both soils the displacement method gave higher results for total salts than either the $1: 1$ or $1: 2$ water extraction. Evidently the addition of these

TABLE 8

Total salts and calcium in Miami silt loam obtained by water extraction and displacement

\begin{tabular}{|c|c|c|c|}
\hline \multirow{2}{*}{ METHOD USED } & \multicolumn{3}{|c|}{ AMOUNT IN THE DRY SOIL } \\
\hline & $\begin{array}{c}\text { Total salts } \\
\text { before ignition }\end{array}$ & $\begin{array}{c}\text { Total salts } \\
\text { after ignition }\end{array}$ & Calcium \\
\hline & p.p. m. & p.p.m. & p.p. $m$. \\
\hline 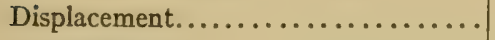 & 261 & 100 & 35.6 \\
\hline $1: 1$ extraction..$\ldots \ldots \ldots \ldots$. & 211 & 83 & 27.1 \\
\hline 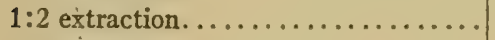 & 234 & 94 & 30.4 \\
\hline $1: 5$ extraction. .............. & 311 & 109 & 38.6 \\
\hline $1: 10$ extraction...$\ldots \ldots \ldots \ldots \ldots$ & 377 & 145 & 60.8 \\
\hline
\end{tabular}

TABLE 9

Total salts and calcium in Carrington silt loam as determined by water extraction and displacement

\begin{tabular}{|c|c|c|c|}
\hline \multirow{2}{*}{ METHOD USED } & \multicolumn{3}{|c|}{ AMOUNT IN THE DRY SOIL } \\
\hline & $\begin{array}{l}\text { Total salts } \\
\text { before ignition }\end{array}$ & $\begin{array}{l}\text { Total salts } \\
\text { after ignition }\end{array}$ & Calcium \\
\hline & $p \cdot p \cdot m$ & p.p.m. & p.p.m. \\
\hline 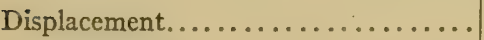 & 551 & 209 & 53.9 \\
\hline $1: 1$ extraction.................... & 450 & 173 & 63.4 \\
\hline $1: 2$ extraction ................... & 470 & 199 & 64.2 \\
\hline $1: 5$ extraction $\ldots \ldots \ldots \ldots \ldots \ldots \ldots . .$. & 582 & 238 & 73.1 \\
\hline 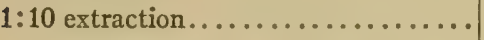 & 646 & 277 & 78.5 \\
\hline
\end{tabular}

amounts of water to the soils caused a greater removal of soluble material from solution than was brought into solution by the solvent action of the water. This removal of material from solution is probably caused largely by precipitation due to the change in the nature of the solvent. When larger quantities of water were used the solvent action was greater than the precipitating effect. The point of balance of these factors will probably vary in different soils. It is probable that on some soils a $1: 1$ water extraction would give higher results than the displacement method. In the two soils studied the 1:5 water extraction gave approximately the same result for total salts as the displacement method. 
More calcium was obtained from Miami silt loam by displacement than by a 1:1 or 1:2 water extraction, but this relation does not hold in the case of the Carrington silt loam. This difference is probably due to the calcium being present in different forms in the two soils. The Miami silt loam used was only very slightly acid, while the Carrington silt loam was strongly acid. Some results obtained with phosphorus on these two soils indicate that the phosphorus content of the soil solution is much lower than would be indicated by the usual water extraction.

The results indicate that the displacement method gives the true soil solution. Further studies of this character should give considerable information regarding the value of the water-extraction method for determining the

TABLE 10

Total salis and nitrate nitrogen in different soils obtained by the water-extraction and displacement methods

\begin{tabular}{|c|c|c|c|c|c|c|}
\hline \multirow{3}{*}{ EIND OF SOIL } & \multicolumn{2}{|c|}{$\mathrm{NO}_{3}$ NITROGEN } & \multicolumn{4}{|c|}{ TOTAL SALTS IN THE DRY SOII } \\
\hline & \multirow{2}{*}{$\begin{array}{c}\text { Displace- } \\
\text { ment }\end{array}$} & \multirow{2}{*}{ Extraction } & \multicolumn{2}{|c|}{ Before ignition } & \multicolumn{2}{|c|}{ After ignition } \\
\hline & & & $\begin{array}{l}\text { Displace- } \\
\text { ment }\end{array}$ & Extraction & $\begin{array}{c}\text { Displace- } \\
\text { ment }\end{array}$ & Extraction \\
\hline & $p . p . m$ & p.p.m. & p.p. $m$. & p.p. $m$. & p.p. $m$. & p.p. $m$. \\
\hline Acid peat... & 791.0 & 840.0 & 7,484 & 11,374 & 2,530 & 3,965 \\
\hline Neutral peat.... & 745.0 & 690.0 & 8,940 & 7,497 & 3,233 & 2,618 \\
\hline Clay loam......... & 75.2 & 71.5 & 747 & 796 & 252 & 281 \\
\hline Superior clay........... & 24.7 & 29.4 & 301 & 370 & 87 & 121 \\
\hline Plainfield sand............. & 22.4 & 18.7 & 275 & 205 & 75 & 60 \\
\hline Hancock sand.......... & 61.2 & 57.0 & 1,512 & 1,400 & 348 & 325 \\
\hline Gray silt loam............ & 9.7 & 10.8 & 161 & 223 & 57 & 124 \\
\hline Miami silt loam. . . . . . . . & 71.0 & 79.8 & 648 & 732 & 222 & 256 \\
\hline Carrington silt loam....... & 54.5 & 48.3 & 512 & .506 & 173 & 168 \\
\hline Waukesha silt loam........... & 30.4 & 30.4 & 340 & 462 & 119 & 186 \\
\hline
\end{tabular}

soluble material in a soil. Before final conclusions can be made regarding the value of the water-extraction method as compared with displacement further investigations will be necessary. These should include determinations of the phosphorus, potassium, calcium and magnesium in a large number of soils by the two methods.

A further comparison of the two methods was made on ten soils by using the 1:5 water extraction on all except the peats. A 1:10 extract was made with the acid peat and a 1:7.5 extract with the neutral peat. The results are shown in table 10 and confirm the conclusions drawn from the preceding data. With some soils the displacement method gave higher results for total salts, while with other soils the water extraction gave the higher results. The results for nitrate nitrogen are the same, within experimental error. 


\section{Discussion of the displacement method}

The results obtained seem to prove that the displacement method gives the true soil solution. It can be used on all soil classes and at a wide range of moisture contents. By using a long soil column small amounts of the soil solution have been obtained from Carrington silt loam at a moisture content of only 6 per cent. The moisture content at which heavy soils can be most conveniently worked is slightly below the optimum for plant growth.

The method has several distinct advantages over other methods which are being used. One of its greatest advantages over the oil pressure method (18) is its simplicity and the fact that it does not require special apparatus. Ordinary glass percolators were entirely satisfactory for most of the work. If it is desirable to reduce the amount of alcohol required the displacement may be started with 200 or $300 \mathrm{cc}$. of alcohol and after this has penetrated the soil, water may be added to complete the displacement.

The greatest advantage it has over water extracts is that it gives a more correct measure of the material in solution. In addition, the solution obtained is about twenty times as concentrated as the water extract. This greatly reduces the time required for evaporation in all determinations. Five cubic centimeters was generally sufficient for a colorimetric nitrate determination and $25 \mathrm{cc}$. for a total salt determination.

The two main disadvantages of the method are the time required for displacement and the necessity of using a larger soil sample than is required by the water-extraction method. The time factor is best controlled by experience and care in packing the soil. About five times as much soil must be used as is required for water extraction.

The method seems to deserve much greater attention than it has received in the past. By its use considerable information may be obtained regarding the concentration, composition, and reaction of the true soil solution. It may also afford information that may be of value in studying results which have been obtained by water extraction and other methods.

Results obtained with the displacement method indicate that at ordinary moisture contents the concentration of the soil solution is inversely proportional to the moisture content of the soil. This does not agree with the conclusions which Bouyoucos and $\mathrm{McCool}$ made from results obtained with the freezing-point method. A study of the freezing-point method was therefore made to determine the cause of this disagreement.

\section{THE FREEZING-POINT METHOD}

The freezing-point method as a means of determining the concentration of the soil solution directly in the soil was first used by Bouyoucos and McCool $(5,6)$. It has since been used by Hoagland $(13)$ in studying changes in the salt content of soils due to seasons and cropping. He compared results obtained by this method with those of Stewart (24) who used the water- 
extraction method. The two methods gave the same general indications regarding the changes which took place in the salt content of the soils, but the water-extraction method gave from 1.5 to 5 times as much total salts as was indicated by the freezing-point method to be actually in the soil solution.

The freezing-point method as a means of measuring the concentration of the soil solution in the soil is based upon the principle that material in solution causes a depression of the freezing point of the solvent. The assumption was made that the finely divided material of the soil does not affect the freezing-point of the soil solution.

In determinations of the freezing-point depressions of soils at varying moisture contents, Bouyoucos and $\mathrm{McCool}(6)$ obtained results which, contrary to what would be expected, indicate that the concentration of the soil solution is not inversely proportional to the moisture content of the soil. The lowering of the freezing point of soils was found to increase approximately in geometric progression as the moisture content decreased in arithmetric progression. This was explained by the following hypothesis:

The hypothesis assumes that a portion of the water found in the soils is inactive and does not take part in dissolving the salts in the soil, and is removed from the field of action as far as the lowering of the freezing point is concerned. Under this assumption the increase of the freezing-point depression is a geometric progression as the percentage of water increases in an arithmetic progression is explained as follows: If a clay soil, for instance, causes 15 per cent of water to become inactive, and this clay at 39 per cent of moisture produces a lowering of the freezing point of $0.075^{\circ} \mathrm{C}$. and at 22 per cent $0.987^{\circ} \mathrm{C}$., then at the former moisture content there is 24 per cent of water free or available to dissolve the salts in the soil, while at the latter water content there is only 7 per cent available for the same purpose. It would be natural, therefore, that the depression of the freezing point would be many times greater at the low moisture content than at the high, than would be expected from the difference in the total moisture content, just as the experimental data really indicate.

This hypothesis also assumes (and the assumption seems to have been proved) that the percentage of inactive water is greater at the low than at the high moisture content and tends to decrease from the former to the latter.

Results obtained with the displacement method indicate that all of the water in the soil acts as a solvent and that there must be another explanation of the results obtained with the freezing-point method.

\section{The concentration of the soil solution at varying moisture contents as determined by the freezing-point and displacement methods}

It has already been shown in tables 4,5 , and 6 that, as determined by the displacement method, the concentration of the soil solution is inversely proportional to the moisture content of the soil. Freezing-point determinations were made at the same time on these soils. Having determined the freezingpoint depression of the soil and of the displaced solution, the value for $K$ can be calculated for both, using the equation $M \cdot D=K$. In each case $M$ is the moisture content of the soil and $D$ is the freezing-point depression of the 
soil or the displaced soil solution. If the concentration of the soil solution is inversely proportional to the moisture content $K$ should be a constant. If $K$ is not a constant it indicates that the concentration of the soil solution is not inversely proportional to the moisture content or that there is another factor influencing the freezing-point depression. The value of $K$ for the displaced solution and the soil should be the same if the freezing-point depression in both cases is caused entirely by the salts in the soil solution. If the values for $K$ are not the same it indicates that there are other factors affecting the freezing-point depression of the soil. The results obtained with Miami silt loam are given in table 11. Results similar to those given were obtained with Plainfield sand and Carrington silt loam.

The data show that the two methods give an entirely different indication of the concentration of the soil solution, particularly at the lower moisture contents, if it is assumed that the depression is due entirely to materialin solution. At a moisture content of 10.30 per cent the freezing-point depression of the soil

TABLE 11

The freesing-point depression of Miami silt loam and the displaced soil solution at different moisture contents

\begin{tabular}{|c|c|c|c|c|}
\hline MOISTURE CONTENT & $\begin{array}{c}\text { FREEZING-POINT } \\
\text { DERRESSION } \\
\text { OF SOIL } \\
\end{array}$ & $\begin{array}{l}\text { FREEZTNG-POINT } \\
\text { DEPRESSION } \\
\text { OF SOLUTION }\end{array}$ & $K$ FOR SOIL & $K$ FOR SOLUTION \\
\hline per cent & ${ }^{\circ} \mathrm{C}$. & ${ }^{\circ} \mathrm{C}$. & & \\
\hline 10.30 & 0.460 & 0.039 & 4.738 & 0.401 \\
\hline 13.55 & 0.257 & 0.030 & 3.482 & 0.406 \\
\hline 17.25 & 0.100 & 0.022 & 1.725 & 0.379 \\
\hline 20.62 & 0.057 & 0.018 & 1.175 & 0.371 \\
\hline 29.41 & 0.028 & 0.013 & 0.676 & 0.382 \\
\hline 34.05 & 0.016 & 0.012 & 0.544 & 0.408 \\
\hline
\end{tabular}

indicates a concentration almost twelve times as great as is indicated by the freezing-point depression of the displaced soil solution. At the highest moisture content the two methods give nearly the same result. There are two possible explanations for the results obtained, viz., (a) the inactive or unfree water, ${ }^{2}$ which is not supposed to act as a solvent, may be displaced and dilute the other portion of the soil solution; (b) the soil may not cause water to become inactive as a solvent but the finely divided solid material of the soil may cause a depression of the freezing point in addition to that caused by materials in solution.

The first explanation is plausible in that it is possible to displace small amounts of the soil solution at such low moisture contents that there would probably be no free water present. However, with this explanation it would be necessary to assume that unfree water is free to move capillarily. In fact, this assumption is necessary if the displacement method gives a true aliquot

${ }^{2}$ In this paper the terms free and unfree or inactive water are used with the meanings attached to them by Bouvouros and $\mathrm{McCool}(6)$, and by Bouyoucos (3). 
of the soil solution. It does not seem probable that a portion of the water would be unable to act as a solvent and at the same time be capable of capillary movement. Therefore, the second explanation may be more nearly correct than the first, as is further indicated in the following.

It is well known that colloidal solutions have the same freezing point as pure water. However, such determinations are not comparable to determinations of the freezing-point depressions of soils in which the amount of liquid present is reduced until it is all in the capillary or film condition. In a review of the literature, the writer did not find any investigations in which a deliberate study was made of the effect of finely divided material on the freezing point when the amount of liquid was so reduced. Foote and Saxton $(11,12)$ however, in studying the forms of water in certain hydrogels by the dilatometer method, recognized that the hydrogels caused a depression of the freezing point of the capillary water. (They defined capillary water as that water which would not freeze at $0^{\circ} \mathrm{C}$, but could be frozen at lower temperatures.) Van Bemmelen and other investigators (27) have shown that water in hydrogels has a low vapor pressure. Zsigmondy, Bachmann, and Stevenson (26) have shown that the same is true for alcohol and benzene in alcogels and benzolgels. If the vapor pressure of a liquid is lowered, its freezing point also is lowered. It therefore seemed probable that the solid material of the soil may cause a depression of the freezing point of the soil solution. The results shown in table 11 indicate that this is the case. In order to obtain more conclusive data on the question, a study was made of the effect of finely divided materials on the freezing point of water, benzene and nitrobenzene. A portion of the results are presented here, but for a more detailed discussion of the procedure and results the reader is referred to another article (20).

In order to study the effect of finely divided materials upon the freezing point of liquids it is desirable to have the solid material as free as possible of substances soluble in the liquids. The materials used fulfilled this requirement very well, as is indicated by the freezing-point depressions at the highest moisture contents.

The $\mathrm{Fe}(\mathrm{OH})_{3}$ was prepared by precipitation with $\mathrm{NH}_{4} \mathrm{OH}$ from a cold dilute solution of the chloride. It was washed free of chlorides, air-dried and ground to pass a 200-mesh screen. The percentage of water in the $\mathrm{Fe}(\mathrm{OH})_{3}$ is expressed on the air-dry basis. In all other cases the percentage of liquid is expressed on the oven-dry basis.

Baker's C. $\mathrm{P} . \mathrm{Al}_{2} \mathrm{O}_{3}$ was used. It contained some material soluble in water but nothing soluble in benzene or nitrobenzene.

\section{The freezing-point depression of water in finely divided material}

The freezing-point depression of water in $\mathrm{Fe}(\mathrm{OH})_{3}$ and Carrington silt loam was determined at varying moisture contents. The results are shown in table 12 . 
The results indicate a considerable depression due to the solid material. The effect due to soluble material was probably small, especially in the case of the $\mathrm{Fe}(\mathrm{OH})_{3}$, since this material gave a depression of only $0.004^{\circ} \mathrm{C}$. at a moisture content of 100 per cent. In order to explain the results obtained with $\mathrm{Fe}(\mathrm{OH})_{3}$ by the hypothesis that it rendered part of the water unfree, it would be necessary to assume that at a moisture content of 15 per cent 14.85 per cent of water was unfree and only 0.15 per cent of water was acting as a solvent as is indicated by the following calculations. Solving for $K$ in the equation $M . D=K$ when $M$ is 100 and $D$ is $0.004^{\circ} \mathrm{C}$, , the value of $K$ is 0.400. Taking this value for $K$ and solving for $M$ when the freezing-point depression is $2.668^{\circ} \mathrm{C}$. one obtains 0.15 as the value of $M$. In this case $M$ is the percentage of water which would be acting as a solvent at the moisture content at which a depression of $2.668^{\circ} \mathrm{C}$. is secured. The inactive water would be obtained by difference and found to be 14.85 per cent. A similar

TABLE 12

The freezing-point depression of water in $\mathrm{Fe}(\mathrm{OH})_{3}$ and in Carrington silt loam at varying moisture contents

\begin{tabular}{c|c|c|c}
\hline \multicolumn{2}{c|}{ Fe $(\mathrm{OH})_{3}$} & \multicolumn{2}{|c}{ CARringtow silt loAu } \\
\hline Moisture content & Freezing-point depression & Moisture content & Freezing-point depression \\
\hline per cent & ${ }^{\circ} \mathrm{C}$. & per cent & ${ }^{\circ} \mathrm{C}$. \\
15.0 & 2.668 & 9.0 & 1.622 \\
17.5 & 1.651 & 11.5 & 0.585 \\
20.0 & 0.393 & 14.0 & 0.315 \\
22.5 & 0.177 & 16.5 & 0.213 \\
25.0 & 0.086 & 21.5 & 0.113 \\
37.5 & 0.016 & 26.5 & 0.062 \\
50.0 & 0.009 & 31.5 & 0.030 \\
100.0 & 0.004 & 46.5 & 0.021 \\
\hline
\end{tabular}

calculation for the soil shows that at a moisture content of 9.0 per cent it would be necessary to assume that only 0.60 per cent water was free and that 8.40 per cent was unfree.

The freezing-point depression of benzene and nitro-benzene in $\mathrm{Al}_{2} \mathrm{O}_{3}$ and Carrington silt loam

The use of organic liquids in which most inorganic salts are insoluble makes it possible to eliminate entirely the depression due to soluble materials. Benzene and nitrobenzene were chosen because they are readily obtained and freeze at a convenient working temperature. The results obtained with these liquids in Carrington silt loam and aluminium oxide are given in tables 13 and 14.

The results are of the same order as was obtained with the same solid material and water. Since there is no material in solution it seems that the 
only possible explanation of the results is that the solid material causes a depression of the freezing point of the liquids when they are in the film or capillary condition, but does not affect their freezing point at contents above saturation. If this is the correct explanation for the results obtained with these liquids it is undoubtedly the explanation for the results obtained with soils. It may therefore be concluded that at ordinary moisture contents the freezing-point depression of the soil solution in the soil is caused by two factors, the material in solution, and the finely divided solid material of the soil.

TABLE 13

The freezing-point depression of benzene in Carrington silt loam and aluminium oxide

\begin{tabular}{c|c|c|c}
\hline \multicolumn{2}{c|}{ CARRINGTon SIT loAar } & \multicolumn{2}{|c}{ ALUMINIUM OXIDE } \\
\hline Benzene & Freezing-point depression & Benzene & Freezing-point depression \\
\hline percent & ${ }^{\circ} \mathrm{C}$. & per cent & ${ }^{\circ} \mathrm{C}$. \\
5.0 & 0.660 & 30.0 & 1.337 \\
7.5 & 0.355 & 35.0 & 0.682 \\
10.0 & 0.150 & 40.0 & 0.492 \\
12.5 & 0.060 & 45.0 & 0.326 \\
15.0 & 0.033 & 50.0 & 0.212 \\
20.0 & 0.025 & 55.0 & 0.115 \\
25.0 & 0.010 & 65.0 & 0.052 \\
37.5 & 0.000 & 75.0 & 0.030 \\
& & 100.0 & 0.000 \\
\hline
\end{tabular}

TABLE 14

The freezing-point depression of nitrobenzene in Carrington silt loam and aluminium oxide

\begin{tabular}{|c|c|c|c|}
\hline \multicolumn{2}{|c|}{ CARRINGTON SILT LOAM } & \multicolumn{2}{|c|}{ ALUMINIUX OXIDE } \\
\hline Nitrobenzene & Freezing-point depression & Nitrobenzene & Freezing-point depression \\
\hline percent & ${ }^{\circ} \mathrm{C}$ & percent & ${ }^{\circ} \mathrm{C}$. \\
\hline 12.5 & 1.630 & 50.0 & 1.720 \\
\hline 15.0 & 1.200 & 60.0 & 1.175 \\
\hline 17.5 & 0.780 & 70.0 & 0.810 \\
\hline 20.0 & 0.510 & 80.0 & 0.580 \\
\hline 25.0 & 0.230 & 90.0 & 0.340 \\
\hline 30.0 & 0.130 . & 100.0 & 0.200 \\
\hline 37.5 & 0.075 & 150.0 & 0.020 \\
\hline 50.0 & 0.000 & 200.0 & 0.000 \\
\hline
\end{tabular}

The relation between the freezing-point depression due to solid material and that due to material in solution

In order to determine whether or not the depression due to solid material and that due to material in solution are additive in their effect on the freezing point, samples of aluminium oxide were moistened with water and other samples were moistened with a sugar solution which had a freezing-point 
depression of $0.126^{\circ} \mathrm{C}$. A sugar solution was used because there is no possibility of a chemical reaction between the sugar and aluminium oxide. If the two factors are additive the difference between the freezing-point depressions at any moisture content should be $0.126^{\circ} \mathrm{C}$., the depression due to sugar. Adsorption may influence the results to some extent. The differences obtained are given in the last column of table 15.

These results and others obtained when sugar solutions and a $\mathrm{Ca}\left(\mathrm{NO}_{3}\right)_{2}$ solution were used in soils, kaolin, silica and ferric hydroxide, prove that the two factors are very nearly additive in their effect on the freezing point. The differences found at the three lower moisture contents are easily within the limit of experimental error, which is quite large at low moisture contents. The presence of sugar did not affect the general order of results.

The results afford further evidence that the great increase in the freezingpoint depression at the lower moisture contents is not due to part of the water being withdrawn from the rôle of a solvent by the solid material. If the

TABLE 15

The freesing-point depression of water and a sugar solution in aluminium oxide at different moisture contents

\begin{tabular}{c|c|c|c}
\hline MOISTURE CONTENT & $\begin{array}{c}\text { TREEZING-POINT } \\
\text { DEPRESSION WITH WATER }\end{array}$ & $\begin{array}{c}\text { FREEZING-PONNT } \\
\text { DEPRESSION WITH } \\
\text { SOLUTION }\end{array}$ & $\begin{array}{c}\text { TREEZING-POINT } \\
\text { DEPRESSION DUE TO } \\
\text { TME SUGAR }\end{array}$ \\
\hline per cent & ${ }^{\circ} \mathrm{C}$. & ${ }^{\circ} \mathrm{C}$. & ${ }^{\circ} \mathrm{C}$. \\
25.0 & 2.118 & 2.290 & 0.172 \\
30.0 & 1.227 & 1.312 & 0.075 \\
35.0 & 0.650 & 0.740 & 0.090 \\
40.0 & 0.370 & 0.500 & 0.130 \\
50.0 & 0.220 & 0.344 & 0.124 \\
75.0 & 0.075 & 0.195 & 0.120 \\
100.0 & 0.053 & 0.173 & 0.120 \\
\hline
\end{tabular}

aluminium oxide had rendered any of the water unfree the solution would have been greatly concentrated at the lower moisture contents and the depression due to the sugar would have been many times that shown in the table. The depression of the freezing point of water at 25 per cent was forty times as great as at 100 per cent. If this had been caused by part of the water being withdrawn from the rôle of a solvent, and the same amount had been withdrawn when the sugar solution was added, the depression of the sugar solution at 25 per cent would have been $6.920^{\circ} \mathrm{C}$. instead of $2.290^{\circ} \mathrm{C}$. The depression due to the sugar alone at this moisture content would have been $4.802^{\circ} \mathrm{C}$. instead of only $0.172^{\circ} \mathrm{C}$, , the experimental value.

\section{The freezing-point depression of soils at their moisture equivalent}

The freezing-point depression of soils at medium to low moisture contents is caused in large part by the solid material. The force which holds the water on the soil particles probably causes the freezing-point depression. If a num- 
ber of soils are subjected to the same centrifugal force, and come to an equilibrium with this force, they will retain different percentages of water. These different percentages of water which are retained will be held with equal forces in the different soils. Since this same force probably causes the freezing-point depression, it should be possible to reduce all soils to the same freezing-point depression, after the removal of soluble salts, by subjecting them to the same centrifugal force.

In a determination of the moisture equivalent of soils the soil is subjected to a centrifugal force of 1000 times gravity. The moisture content after centrifuging is that at which the force of attraction between the soil and water is equal to this centrifugal force. In this manner the force holding water in different soils may be brought to a uniform value. Therefore the freezingpoint depression of the soils, due to solid material, should be equal at the moisture contents represented by their moisture equivalents.

TABLE 16

The freezing-point depression of washed soils at their moisture equivalent

\begin{tabular}{|c|c|c|}
\hline SOIL & $\begin{array}{l}\text { MOISTURE } \\
\text { EQUTVALENT }\end{array}$ & $\begin{array}{l}\text { FREEZING-POINT } \\
\text { DEPRESSION }\end{array}$ \\
\hline & & ${ }^{\circ} \mathrm{C}$. \\
\hline 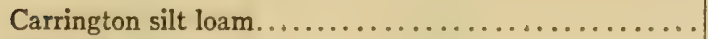 & 21.57 & 0.055 \\
\hline 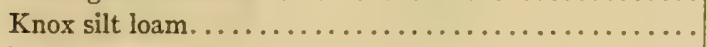 & 25.40 & 0.057 \\
\hline Mellen loam.................... & 16.39 & 0.053 \\
\hline Superior clay.......................... & 21.84 & 0.061 \\
\hline Plainfield sand...$\ldots \ldots \ldots \ldots \ldots \ldots \ldots$ & 4.73 & 0.076 \\
\hline 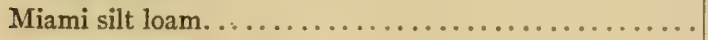 & 26.47 & 0.052 \\
\hline 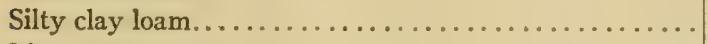 & 33.29 & 0.061 \\
\hline Fine sandy loam............... & 12.49 & 0.057 \\
\hline Peat................. & 111.60 & 0.061 \\
\hline Kaolin....................... & 38.12 & 0.046 \\
\hline 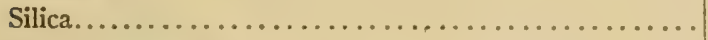 & 19.14 & 0.057 \\
\hline Aluminium oxide...$\ldots \ldots \ldots \ldots \ldots \ldots \ldots$ & 21.56 & 0.043 \\
\hline
\end{tabular}

In order to determine the freezing-point depression due to solid material it is necessary to remove the soluble material as far as possible. One-hundredgram samples of different soils, silica, kaolin and aluminium oxide were washed with 1200 to $1500 \mathrm{cc}$. of distilled water to remove soluble salts. The samples were then dried in an electric oven at $105^{\circ} \mathrm{C}$. The moisture equivalent was determined in the usual manner. After centrifuging the freezing-point determinations were made on the soils. The speed of the centrifuge was slightly less than that which gives a force of 1000 times gravity. This caused slightly high results for the moisture equivalent and hence low results for the freezingpoint depression, due to solid material, at the true moisture equivalent. There were undoubtedly several sources of error, such as the incomplete removal of the soluble material, puddling in making the determination of the moisture equivalent, and evaporation in transferring the soil from the moisture cups to the freezing-point tubes. The results are shown in table 16. 
The results indicate that at the moisture equivalent the depression of the freezing point due to solid material is very nearly the same in different soils and certain artificial materials. This can be explained only by the assumption that the same force which retains the moisture causes the freezing-point depression. The values are not exactly the same but are within experimental error. The low values for kaolin and aluminium oxide are probably due to the fact that these materials pack very tightly in the centrifuge preventing the water from being readily thrown out. The high result for the Plainfield sand may be due to the extreme readiness with which the water is removed from such a coarse soil.

The results indicate that the freezing-point method could be used to determine the salt content of soils at their moisture equivalent. At the moisture equivalent the depression due to solid material is probably a constant, about $0.050^{\circ} \mathrm{C}$. By determining the freezing-point depression of a soil at its moisture equivalent and subtracting this constant, the freezing-point depression due to soluble material would be obtained. In using such a procedure great care should be taken that the true moisture equivalent is used in all cases, for a slight error in the moisture content would decidedly affect the freezingpoint depression due to solid material. This procedure is rather long, so it is doubtful if it would be of much value. If the freezing-point method is used it would be more convenient and probably more accurate to make the determinations at moisture contents above saturation, entirely eliminating the depression caused by the solid material.

\section{Discussion of the freezing-point method}

The freezing-point method does not give a measure of the concentration of the soil solution in the soil at ordinary moisture contents, for it has been shown that finely divided material causes a depression of the freezing point of a liquid in the film or capillary condition. The force holding the liquid on the solid material and causing the freezing-point depression is adhesion. When the amount of water in the soil is increased a point is reached at which some of the soil solution is so distant that this force no longer affects its freezing point. This point is probably the point of saturation. Probably at any moisture content below saturation the solid material causes a depression of the freezing point of the soil solution. At moisture contents above saturation the depression becomes due entirely to material in solution.

The freezing-point method has been used by Bouyoucos and his associates to determine the lime requirement of soils (1), the velocity of reactions between soils and chemical reagents (4), the solubility of soils (2), and the absolute salt content of soils (7). In these investigations the moisture content was always very high, varying from 66 to several hundred per cent. At those moisture contents the depression is due entirely to materials in solution and the method gives a satisfactory measure of the soluble material present. It is well adapted to such studies and used under these conditions has given valuable results. 


\section{SUMMARY}

It is desirable in studying problems of soil fertility, plant nutrition and related subjects to have a method with which the true soil solution may be obtained from a soil at ordinary moisture contents in sufficient quantities for analytical work. In a review of the literature it was found that Ischerekov (15), using the displacement method, obtained results which indicate that the method gives the true soil solution in quantities sufficient for most purposes. Hence it seemed desirable to make a study of the method and compare it with other methods which are now being used in studying the concentration and composition of the soil solution.

The method consists of packing the moist soil in a cylinder provided with an outlet at the bottom. Ethyl alcohol is then poured on top of the soil column and as it penetrates the soil it displaces some of the soil solution which forms a zone of saturation below the alcohol. This zone increases in depth as it is continually forced downward by the alcohol. When the saturated zone reaches the bottom of the soil column the clear soil solution, free of alcohol, drops from the soil as gravitational water.

A study was made of the effect of different displacing liquids on the time required for displacement, the percentage of the soil solution displaced and the composition of the displaced solution. The concentration of successive portions of the displaced soil solution was determined and also the concentration of the soil solution obtained from the soils at different moisture contents. The amount of total salts, nitrates, and calcium obtained from the soil by displacement was compared with the amount secured from the soil by water extraction.

Results obtained with the displacement method did not agree with the conclusions of Bouyoucos and McCool (6), drawn from a study of the freezing-point depressions of soils, with regard to the concentration of the soil solution at different moisture contents and the forms of water in the soil. Therefore a study was made of the freezing-point method and factors affecting the freezing-point depression of the soil solution in the soil. The effect of finely divided material on the freezing point of water, benzene and nitrobenzene was studied. A summary of the results and conclusions is given below.

(a) Ethyl alcohol was found to be more satisfactory as a displacing liquid than water, methyl alcohol, acetone, or liquids non-miscible with water.

(b) The composition of the soil solution obtained by displacement was not influenced by the displacing liquid used.

(c) Successive portions of the displaced solution gave the same freezingpoint depression and contained the same amount of total salts.

(d) The concentration of the displaced solution was found to be inversely proportional to the maisture content of the soil.

(e) The displacement method gave the same amount of nitrate nitrogen and approximately the same amount of total salts as a 1:5 water extraction of the soil. 
(f) The method seems to be well adapted to a study of the composition and reaction of the soil solution under any condition.

(g) Finely divided material was found to cause a depression of the freezing point of water, benzene, and nitrobenzene when the amount of liquid was reduced until it was in the film or capillary condition.

(h) The freezing-point method does not give a measure of the concentration of the soil solution directly in the soil at ordinary moisture contents of the soil.

(i) At high moisture contents, probably only above saturation, the freezing-point method gives a measure of the concentration of the soil solution.

(j) The freezing-point depression due to solid material at the moisture equivalent was found to be very nearly a constant for a number of soils.

(k) A soil does not cause a considerable amount of water to be removed from the role of a solvent, as has sometimes been assumed.

A subsequent article will be devoted to the classification of the soil moisture

\section{REFERENCES}

(1) Bouroucos, G. J. 1916 The freezing point method as a new means of determining the nature of soil acidity and the lime requirement of soils. Mich. Agr. Exp. Sta. Tech. Bul. 27.

(2) Bouyoucos, G. J. 1919 Rate and extent of solubility of soils under different treatments and conditions. Mich. Agr. Exp. Sta. Tech. Bul. 44.

(3) Bouroucos, G. J. 1921 A new classification of the soil moisture. In Soil Sci., v. 11 , no. 1 , p. 33-49.

(4) Bouyoucos, G. J., and Laudeman, W. A. 1917 The freezing point method as a new means of studying the velocity of reaction between soils and chemical reagents and the behavior of equilibrium. Mich. Agr. Exp. Sta. Tech. Bul. 37 .

(5) Bouyoucos, G. J., And McCoor, M. M. 1915 The freezing point method as a new means of measuring the concentration of the soil solution directly in the soil. Mich. Agr. Exp. Sta. Tech. Bul. 24.

(6) Bouroucos, G. J., AND McCool, M. M. 1916 Further studies on the freezing-point lowering of soils. Mich. Agr. Exp. Sta. Tech. Bul. 31.

(7) Bouyoucos, G. J., AND McCool, M. M. 1918 Determining the absolute salt content of soils by the freezing point method. In Jour. Agr. Res., v. 15, p. 331-336.

(8) Briggs, L. J., ANd McCall, A. G. 1904 An artificial root for inducing capillary movement of soil moisture. In Science, v. 20 , p. 566-569.

(9) Cavers, F. G. 1914 Gola's theory of Edaphism. In Jour. Ecol., v. 2, p. 217.

(10) Davis, R. O. E., and Bryan, H. 1910 An electrical bridge for the determination of soluble salts in soils. U. S. Dept. Agr. Bur. Soils Bul. 61.

(11) Foote, H. W., ANd SAxton, B. 1916 The effect of freezing on certain inorganic hydrogels. I. In Jour. Amer. Chem. Soc., v. 38, no. 3, p. 588-609.

(12) Foote, H. W., AND SAXTON, B. 1917 The effect of freezing on certain inorganic hydrogels: II. In Jour. Amer. Chem. Soc., v. 39, no. 6, p. 1103-1125.

(13) Hoagland, D. R. 1918 The freezing-point method as an index of variations in the soil solution due to season and crop growth. In Jour. Agr. Res., v. 12, no. 6, p. 369-395.

(14) Hoagland, D. R., Martin, J. C., and Stewart, G. R. 1920 Relation of the soil solution to the soil extract. In Jour. Agr. Res., v. 20, no. 5, p. 381-395. 
(15) Ischerekov, V. 1907 Obtaining the soil solution in an unaltered condition. In Zhur. Opuitn. Agron. (Russ. Jour. Exp. Landw.), v. 8, p. 147-166.

(16) Lipman, C. B. 1918 A new method of extracting the soil solution. Univ. Cal. Pub. Agr. Sci., v. 3, no. 7, p. 131-134.

(17) Mrtscherlich, E. A. 1907 Eine chemishe Bodenanalyse für pllanzenphysiologische Forschungen. In Landw. Jahrb., Bd. 36, p. 309-369.

(18) Morgan, J. F. 1916 The soil solution obtained by the oil pressure method. Mich. Agr. Exp. Sta. Tech. Bul. 28.

(19) Northrup, Z. 1918 The true soil solution. In Science, v. 47, p. 638-639.

(20) Parker, F. W. 1921 The effect of finely divided material on the freezing point of water, benzene, and nitrobenzene. In Jour. Amer. Chem. Soc., v. 43, No. 5, p. 1011-1018.

(21) Ramann, E., März, S., And Bauer, H. 1916 The soil solution obtained by the action of a hydraulic press. In Internat. Mit. Bodenk., Bd. 6, p. 27; abs. in Chem. Abs., v. 11, p. 3078. (Original not seen.)

(22) Schloesing, Tr. 1866 Sur l'analse des principes solubles de la terre vegetale. In Compt. Rend. Acad. Sci. (Paris), t. 63, p. 1007.

(23) Schreiner, O., and Failyer, G. H. 1905 Colorimetric, turbidity, and titration methods used in soil investigations. U. S. Dept. Agr. Bur. Soils Bul. 31, p. 16-17.

(24) Stewart, G. R. 1918 Effect of season and crop growth on modifying the soil extract. In Jour. Agr. Res., v. 12, no. 6, p. 311-369.

(25) Van Suchtelen, F. H. H. 1912 Methode zur Gewinnung der natürlichen bodenlösung. In Jour. Landw., Bd. 60, p. 669-70.

(26) Zsigmondy, R., Bachmann, W., and Stevenson, E. J. 1912 Ueber einen Apparat zur Bestimmung der Dampfspannungsisothermen des Gels der Kieselsaüre. In Ztschr. Anorg. Chem., Bd. 75, p. 189-197.

(27) Zsigmondy, D., and Spear, E. B. 1917 The Chemistry of Colloids., chap. 7. Wiley, New York. 



\section{LIBRARY OF CONGRESS
|}

min

00027817579 